\title{
Supplementation with nanomolar concentrations of verbascoside during in vitro maturation improves embryo development by protecting the oocyte against oxidative stress: a large animal model study
}

\author{
Nicola Antonio Martino ${ }^{\mathrm{a}, \mathrm{b}, *, 1}$, Federica Ariu ${ }^{\mathrm{c}, 1}$, Daniela Bebbere ${ }^{\mathrm{c}}$, Manuel Filioli Uranio ${ }^{\mathrm{a}}$, \\ Adriana Chirico ${ }^{\mathrm{a}}$, Giuseppina Marzano ${ }^{\mathrm{a}}$, Anna Maria Sardanelli ${ }^{\mathrm{e}, \mathrm{f}}$, Angela Cardinali ${ }^{\mathrm{d}}$, \\ Fiorenza Minervini $^{\mathrm{d}}$, Luisa Bogliolo ${ }^{\mathrm{c}, 1}$, Maria Elena Dell'Aquila ${ }^{\mathrm{a}, 1}$ \\ a Department of Biosciences, Biotechnologies and Biopharmaceutics (DBBB), University of Bari Aldo Moro, Str. Prov. Casamassima Km 3, 70010, Valenzano, \\ Bari, Italy \\ ${ }^{\mathrm{b}}$ Istituto Zooprofilattico Sperimentale di Puglia e Basilicata, Via Manfredonia 20, 71121 Foggia, Italy \\ ${ }^{c}$ Obstetrics and Gynecological Section, Department of Veterinary Medicine, Via Vienna, $n^{\circ} 207100$ Sassari, Italy \\ ${ }^{\mathrm{d}}$ Institute of Sciences of Food Production (ISPA), National Research Council of Italy (CNR), Via G. Amendola 122/O, 70125 Bari, Italy \\ e Department of Basical Medical Sciences, Neurosciences and Sensory Organs, University of Bari Aldo Moro, P.zza G. Cesare, 11, 70124 Bari, Italy \\ ${ }^{\mathrm{f}}$ Institute of Translational Pharmacology (IFT), National Research Council of Italy (CNR) via del Fosso del Cavaliere 100, 00133 Rome, Italy
}

\section{A R T I C L E I N F O}

\section{Article history:}

Received 26 February 2016

Received in revised form 27 July 2016

Accepted 10 August 2016

Available online 10 August 2016

\section{Keywords:}

Verbascoside

IVM

Juvenile sheep oocyte

Blastocyst development

Oocyte bioenergetics and oxidative stress

\begin{abstract}
A B S T R A C T
The effects of verbascoside (VB), added at nanomolar concentrations during in vitro maturation (IVM) of juvenile sheep oocytes, on in vitro embryo development and its mechanisms of action at the oocyte level were analyzed. Developmental rates, after IVM in the presence/absence of VB ( $1 \mathrm{nM}$ for $24 \mathrm{~h} ; 1 \mathrm{nM}$ for $2 \mathrm{~h}$; $10 \mathrm{nM}$ for $2 \mathrm{~h}$ ), were evaluated. The bioenergetic/oxidative status of oocytes matured after IVM in the presence/absence of $1 \mathrm{nM}$ VB for $24 \mathrm{~h}$ was assessed by confocal analysis of mitochondria and reactive oxygen species (ROS), lipid peroxidation (LPO) assay, and quantitative PCR of bioenergy/redoxrelated genes. The addition of $1 \mathrm{nM}$ VB during $24 \mathrm{~h}$ IVM significantly increased blastocyst formation and quality. Verbascoside reduced oocyte ROS and LPO and increased mitochondria/ROS colocalization while keeping mitochondria activity and gene expression unchanged. In conclusion, supplementation with nanomolar concentrations of VB during IVM, in the juvenile sheep model, promotes embryo development by protecting the oocyte against oxidative stress.
\end{abstract}

(c) 2016 Elsevier Inc. All rights reserved.

\section{Introduction}

Recent studies have demonstrated that some polyphenols, phytochemical compounds present in fruit and vegetables, show disease-preventing properties, such as anticarcinogenic, antimu-

\footnotetext{
* Corresponding author at: Department of Biosciences, Biotechnologies and Biopharmaceutics (DBBB), University of Bari Aldo Moro, Str. Prov. Casamassima km 3, 70010 Valenzano (BA), Italy.

E-mail addresses: nicmartino@libero.it (N.A. Martino), federica@uniss.it (F. Ariu), dbebbere@uniss.it (D. Bebbere), m.filioliuranio@gmail.com (M.F. Uranio), adriana.chirico@gmail.com (A. Chirico), ros.marzano@gmail.com (G. Marzano), annamaria.sardanelli@uniba.it (A.M. Sardanelli), angela.cardinali@ispa.cnr.it (A. Cardinali), fiorenza.minervini@ispa.cnr.it (F. Minervini), luis@uniss.it (L. Bogliolo), mariaelena.dellaquila@uniba.it (M.E. Dell'Aquila).

1 These authors contributed equally to this work.
}

tagenic, anti-inflammatory and antioxidant activities, as assayed by in vivo and in vitro models $[1,2]$. Verbascoside (VB) or acteoside is a polyphenol belonging to the family of phenyl propanoids. It is present in plants widely cultivated in the Mediterranean area [1,3], especially Aloysia citrodora and Olea europea, whose fruits and derived-products are widespread in the so-called "Mediterranean diet". Verbascoside is structurally characterized by a caffeic acid linked by a $\beta$-(D)-glucopyranoside to 4,5-hydroxyphenylethanol (hydroxytyrosol) bound through ester and glycosidic links, with a rhamnose in sequence [1-3] to the glucose molecule [3] and has been reported as showing antioxidant effects in animal experiments as well as in human clinical studies $[1,2]$.

The antioxidant effects of VB observed in several cell systems have been related to different mechanisms of action: (1) short-term reactive oxygen species (ROS) scavenging effects, due to prevention of ROS-related damage in different ways, such as by interfering with 
initial ROS-generating reactions, or by scavenging the free oxygen molecules required to begin ROS production, or by chelating metals that speed up oxidative processes [2-5]; or (2) long-term genomic effects for up-regulation of endogenous detoxifying systems $[2,4-6]$ or down-regulation of genes coding for pro-oxidant enzymes $[2,7]$. As reported in current literature, the biological mechanisms activated by VB seem to be mediated by linking to different receptor types, such as membrane, cytosolic and nuclear receptors, depending on cell type and functional status [2,7,8-10].

In Assisted Reproductive Technologies (ARTs), there is a need to establish reliable and affordable in vitro treatments with antioxidants for gametes and embryos from women with oxidative stress-based reproductive pathologies or environmental exposure or lifestyle-related fertility decline [11-13]. Additionally, antioxidants may improve the outcome of oocyte in vitro maturation (IVM), in vitro fertilization (IVF), intracytoplasmic sperm injection (ICSI), in vitro embryo culture (IVEC), oocyte and embryo cryopreservation. Indeed, it is well known that oocytes and embryos are vulnerable to oxidative stress conditions occurring in vivo [13] or induced by in vitro culture systems [13]. Various synthetic and natural antioxidants have been added to in vitro culture systems to improve the maturation of oocytes and the developmental competence of preimplantation embryos [14-25]. In recent years, naturally occurring antioxidants are receiving renewed interest because they occur in nature, in many cases being derived from plant sources and presumed to be safe [18]. For instance, beneficial effects on embryo development have been reported after addition of anthocyanin [19], melatonin [20,21] resveratrol [22-24] and sericin [25] during IVM.

Ruminant in vitro models are increasingly being considered as very relevant for human preimplantation reproductive research [26-28]. The ovine, a monovular species like human, could potentially represent an optimal animal model, being closer to human reproductive physiology than other species [29]. Because these models are not hampered by restrictive ethical constraints, they provide great support to research into fertility preservation in women of reproductive age and in prepubertal girls [30-32].

In a previous study performed in the juvenile sheep model, we reported that $\mathrm{VB}$, added at micromolar concentrations using a continuative $24 \mathrm{~h}$ IVM exposure protocol, acted as a prooxidant molecule, by impairing oocyte bioenergetic potential and oxidative status and embryo developmental competence. This prooxidant activity was hypothesized to be due to an excessively high tested concentration, as suggested by uptake data and/or by prolonged exposure time in culture media $(24 \mathrm{~h})$ which probably induced $\mathrm{H}_{2} \mathrm{O}_{2}$ production [33]. Thus, it highlighted the need to evaluate whether lower VB concentrations may exert antioxidant effects.

The first aim of the present study was to test, in the same juvenile sheep model, the effects of supplementation with low (nanomolar) concentrations of VB during IVM on oocyte meiotic and developmental competence. Because significant improvements to embryo yield and quality were observed, we thereafter investigated whether these effects could be determined by the antioxidant activity of VB on in vitro matured oocytes.

\section{Materials and methods}

\subsection{Chemicals}

All chemicals for in vitro cultures and analyses were purchased from Sigma-Aldrich (Milan, Italy) unless otherwise indicated. Verbascoside was extracted, purified and quantified following a previously described protocol [34]. Verbascoside was added at the concentrations of $1 \mathrm{nM}$ and $10 \mathrm{nM}$. These concentrations were selected on the basis of previous studies reporting that follow- ing ingestion, plasmatic levels of polyphenolic compounds rarely exceed nanomolar concentrations [2]. A stock solution of $1 \mu \mathrm{M} \mathrm{VB}$ was prepared by dissolving lyophilized VB in TCM-199 and stored at $-20^{\circ} \mathrm{C}$. Working solutions of $1 \mathrm{nM}$ and $10 \mathrm{nM}$ VB were prepared on the day of use.

\subsection{Oocyte collection}

Ovaries from sheep under 6 months of age were recovered at local slaughterhouses and processed by the slicing procedure as previously described $[35,36]$. Only cumulus-oocyte complexes (COCs) with intact cumulus cell layers and homogeneous cytoplasm were selected.

\subsection{In vitro maturation (IVM)}

In vitro maturation was performed following previously reported procedures $[35,37]$. Briefly, selected COCs were matured in vitro in TCM 199 supplemented with 10\% heat-treated oestrus sheep serum (OSS), $0.1 \mathrm{IU} / \mathrm{mL}$ FSH, $0.1 \mathrm{IU} / \mathrm{mL}$ LH and $100 \mathrm{mM}$ cysteamine for $24 \mathrm{~h}$ at $38.5^{\circ} \mathrm{C}$ under $5 \% \mathrm{CO}_{2}$ in air. Verbascoside was added at the concentrations and exposure times as reported in the experimental design.

\subsection{In vitro fertilization (IVF) and in vitro embryo culture (IVEC)}

As described by Bogliolo et al. [35] in vitro matured oocytes were fertilized in Synthetic Oviductal Fluid (SOF; [38]) with 2\% oestrous sheep serum (OSS), $1 \mu \mathrm{g} / \mathrm{mL}$ heparin, $1 \mu \mathrm{g} / \mathrm{mL}$ hypotaurine for $22 \mathrm{~h}$ at $38.5^{\circ} \mathrm{C}$ and under a $5 \% \mathrm{CO}_{2}, 5 \% \mathrm{O}_{2}, 90 \% \mathrm{~N}_{2}$ atmosphere in fourwell Petri dishes with frozen-thawed spermatozoa selected by the swim-up technique $\left(1 \times 10^{6}\right.$ spermatozoa $\left./ \mathrm{mL}^{-1}\right)$. Presumptive zygotes were cultured for 8 days in four-well Petri dishes in SOF with essential and nonessential amino acids at oviductal concentration [39] and 0.4\% Bovine Serum Albumin (BSA) under mineral oil, in maximum humidified atmosphere with $5 \% \mathrm{CO}_{2}, 5 \% \mathrm{O}_{2}, 90 \%$ $\mathrm{N}_{2}$ at $38.5^{\circ} \mathrm{C}$. The cleavage rate was recorded at $30 \mathrm{~h}$ after IVF.

\subsection{Nuclear chromatin evaluation of oocytes}

To evaluate nuclear chromatin, oocytes underwent cumulus cell removal by incubation in TCM-199 with $20 \%$ FCS and $80 \mathrm{IU}$ hyaluronidase $/ \mathrm{mL}$ and aspiration in and out of finely drawn glass pipettes. Oocytes were stained with $2.5 \mu \mathrm{g} / \mathrm{mL}$ Hoechst 33258 in 3:1 (v/v) glycerol/phosphate buffered saline (PBS) solution and mounted on microscope slides covered with cover slips, sealed with nail polish, and kept at $4{ }^{\circ} \mathrm{C}$ in the dark until observation. Oocytes were evaluated in relation to their meiotic stage under an epifluorescence microscope (Nikon Eclipse 600, 400× magnification) equipped with the B-2A ( $346 \mathrm{~nm}$ excitation/460 nm emission) filter, as germinal vesicle (GV), metaphase to telophase I (MI to TI), MII with 1 st polar body (PB) extruded, or degenerated [36].

\subsection{Blastocyst evaluation and cell count}

Blastocyst formation was assessed at day 8 and blastocysts were classified according to degree of expansion and hatching status [40]: blastocyst (normal blastocyst with a blastocoel equal or up to half of the embryo volume), expanded blastocyst (a large blastocyst with a blastocoel greater than half of the embryo volume or blastocyst with a blastocoel completely filling the embryo), and hatching blastocyst (hatching or already hatched blastocyst). Analysis of blastocyst cell number was performed by differential staining of the inner cell mass (ICM) and trophectoderm (TE) cell compartments [35]. To differentially stain ICM and TE nuclei, blastocysts derived from treated and control groups were exposed to $1 \%$ Triton X-100 
in $20 \mathrm{mM}$ HEPES-buffered TCM 199 containing $30 \mathrm{mg} / \mathrm{mL}$ propidium iodide (PI) for 35-40 s. The blastocysts were then transferred into ice-cold ethanol for 2-5s. Finally, the blastocysts were incubated in medium with $50 \%(\mathrm{v} / \mathrm{v})$ glycerol and ethanol containing $0.1 \mathrm{mg} / \mathrm{mL}$ bis-benzimide (Hoechst 33342) for $5 \mathrm{~min}$. The blastocysts were directly mounted into a small droplet of glycerol on a glass slide and examined under epifluorescent microscope (Olympus IX70, Italy). A digital image of each embryo was taken, and the numbers of TE (red) and ICM (blue) nuclei were counted. The intense pink colour represents the chromatin in nuclei of permeabilized TE cells, that are stained both red (PI) and blue (Hoechst 33342). ICM nuclei remain blue because these cells were not permeabilized [41].

\subsection{Evaluation of oocyte bioenergetic/oxidative status}

After IVM, COCs underwent cumulus cell removal and denuded oocytes were washed three times in PBS with 3\% BSA and incubated for $30 \mathrm{~min}$ in the same medium containing $280 \mathrm{nM}$ MitoTracker ${ }^{\circledR}$ Orange CMTM Ros (Molecular Probes M-7510, Oregon, USA) at $38.5^{\circ} \mathrm{C}$ under $5 \% \mathrm{CO}_{2}$ [36] in order to detect actively respiring mitochondria (mt). After incubation with MitoTracker probe, oocytes were washed three times in PBS with 0.3\% BSA and incubated for $15 \mathrm{~min}$ in the same media containing $10 \mu \mathrm{M} 2^{\prime}, 7^{\prime}-$ dichlorodihydrofluorescein diacetate $\left(\mathrm{H}_{2}\right.$ DCF-DA) [36] in order to localize intracellular sources of ROS. After incubation, oocytes were washed three times in pre-warmed PBS without BSA and fixed overnight at $4{ }^{\circ} \mathrm{C}$ with $2 \%$ paraformaldehyde solution in PBS. Staining with Hoechst 33258 and mounting on slides were performed as described above. Metaphase II (MII) stage oocytes (showing the 1 st PB extruded and the MII plate) were selected among those having regular ooplasmic size and texture (no vacuoles) for evaluation of mt distribution pattern and were observed at $600 \times$ magnification in oil immersion with a Nikon C1/TE2000-U laser scanning confocal microscope. A helium/neon laser ray at $543 \mathrm{~nm}$ and the G-2A filter ( $551 \mathrm{~nm}$ exposure and $576 \mathrm{~nm}$ emission) were used to point out the MitoTracker Orange CMTM Ros. An argon ion laser ray at $488 \mathrm{~nm}$ and the B-2A filter (495 nm exposure and $519 \mathrm{~nm}$ emission) were used to point out the DCF. Scanning was conducted with 25 optical series from the top to the bottom of the oocyte with a step size of $0.45 \mu \mathrm{m}$ to allow three-dimensional distribution analysis. General criteria for oocyte mt pattern definition included heterogeneous (peri-nuclear and/or sub-cortical, $\mathrm{P} / \mathrm{S}$ ) $\mathrm{mt}$ distribution pattern, indicating a metabolically active ooplasm, or homogeneous (small aggregates, SA) mt distribution pattern, considered as an indication of immature cytoplasmic condition. Oocytes showing irregular distribution of large mt clusters unrelated to the specific cell compartments were classified as abnormal [36]. Measurements of fluorescence intensities were performed in ooplasms of MII oocytes having either $\mathrm{P} / \mathrm{S}$ or SA mt distribution pattern whereas oocytes showing abnormal $\mathrm{mt}$ distribution pattern were excluded from quantification analysis. In each sample, MitoTracker and DCF fluorescence intensities were measured at the equatorial plane, with the aid of the EZ-C1 Gold Version 3.70 image analysis software platform for Nikon C1 (Nikon Instruments) confocal microscope, as in previous studies from our unit $[33,36]$. For measurements of oocyte fluorescence intensities, a circle area was drawn to measure only the cytoplasmic area. The fluorescence intensity encountered within the programmed scan area was recorded and plotted against the conventional pixel unit scale (0-255), fluorescence intensity was expressed as arbitrary densitometric units (ADU) and parameters related to fluorescence intensity were maintained at constant values for all measurements. Images were taken under fixed scanning conditions with respect to laser energy, signal detection (gain), and pinhole size. Degree of colocalization was reported quantifying the overlap degree between
MitoTracker ${ }^{\circledR}$ Orange CMTM Ros and DCF fluorescence signals and was expressed as overlap coefficient [35]. Confocal assessment of fluorescence intensities of mt-specific $[28,33,36,42,43]$ and ROSspecific probes [22-24,33,36] were reported as efficient tools to assess oocyte mt activity and intracellular ROS levels. In addition, mt/ROS colocalization was reported as a biomarker of healthy oocytes $[33,36,44]$.

\subsection{Oocyte lipid peroxidation (LPO) assay}

The thiobarbituric acid-reactive substance (TBARS) assay (OxiSelect ${ }^{\mathrm{TM}}$ TBARS Assay kit, Cell Biolabs, Inc. San Diego, CA, USA) was used for monitoring lipid peroxidation(LPO). Malondialdehyde (MDA), a by-product of LPO, forms a 1:2 adduct with thiobarbituric acid (TBA) which was measured colorimetrically using an MDA equivalent standard. Butylated hydroxytoluene (BHT) at $1 \mathrm{X}$ final concentration was added to each test sample to prevent further lipid oxidation during sample processing and the TBA reaction. After that, oocytes were lysated by $5-10$ cycles of freezing in liquid nitrogen and thawing in $\mathrm{H}_{2} \mathrm{O}$ at $100^{\circ} \mathrm{C}$. Samples were incubated for $5 \mathrm{~min}$ at room temperature in sodium dodecylsulphate (SDS) lysis solution to denature the proteins; then, TBA was added and samples were incubated for $50 \mathrm{~min}$ at $95^{\circ} \mathrm{C}$. Tubes were cooled to room temperature in an ice bath for $5 \mathrm{~min}$. All sample tubes were centrifuged at $735 \times g$ for $15 \mathrm{~min}$. The supernatants were removed and samples and MDA standards $(200 \mu \mathrm{L})$ were transferred to a 96-well microplate compatible with a Victor X, Perkin Elmer multilabel plate reader. Blank control ( $0 \mu \mathrm{M}$ MDA) was included and subtracted. Samples were read at $490 \mathrm{~nm}$ [45].

\subsection{Gene expression analysis}

RNA samples were isolated from pools of 10 denuded MIIoocytes. The relative expression of BCL2-associated $X$ protein (BAX, pro-apoptotic), Glyceraldehyde 3-Phosphate Dehydrogenase (GAPDH, energy metabolism), Heat Shock Protein 90KDa beta (HSP90B, protein degradation prevention) and Superoxide Dismutase 1 (SOD1, antioxidant activity) was analyzed. Total RNA was isolated from oocytes with RNeasy Micro Kit (Qiagen, Hilden, Germany) following manufacturer's instructions. Five pg luciferase mRNA (Promega) were added to each group prior to RNA extraction to account for RNA loss during the isolation process. During the procedure, RNA was treated with DNase I to exclude any potential genomic DNA contamination. RNA isolated from oocytes was entirely and immediately used for reverse transcriptionpolymerase chain reaction (RT-PCR). Reverse transcription was performed in a final volume of $20 \mu \mathrm{L}$, consisting of $50 \mathrm{mM}$ Tris- $\mathrm{HCl}$ (pH 8.3), $75 \mathrm{mM} \mathrm{KCl}, 3$ mM MgCl 2,5 mM DTT, 1 mM dNTPs, $2.5 \mu \mathrm{M}$ random hexamer primers, $0.05 \mu \mathrm{g}$ oligo (dT) 18 primers, 20 U RNase OUT and $100 \mathrm{U}$ SuperScript III RT (all purchased at Invitrogen Corporation, Carlsbad, CA). Reaction tubes were incubated at $25^{\circ} \mathrm{C}$ for $10 \mathrm{~min}$, then at $42^{\circ} \mathrm{C}$ for $1 \mathrm{~h}$ and finally at $70^{\circ} \mathrm{C}$ for $15 \mathrm{~min}$ to inactivate the reaction. One tube without RNA and one with RNA, but without reverse transcriptase, were analyzed as negative controls. To quantify the RNA recovery rate, $5 \mathrm{pg}$ of luciferase mRNA (not subjected to RNA isolation) were subjected to cDNA synthesis as well. Primers for all studied genes are listed in Supplementary file 1, panel A. Relative quantification of transcripts was performed by Real Time RT-PCR in a 7900HT Real-Time PCR System (Applied Biosystems Foster City, CA, USA). PCR was performed in a $15 \mu \mathrm{L}$ reaction volume containing $7.5 \mu \mathrm{L} 2 \times$ SYBR Green PCR Master Mix (Applied Biosystems), $200 \mathrm{nM}$ of each primer and cDNA equivalent to 0.25 oocytes or $5 \mathrm{ng}$ RNA. PCR protocol consisted in two incubation steps $\left(50^{\circ} \mathrm{C}\right.$ for $5 \mathrm{~min}$ and $95^{\circ} \mathrm{C}$ for $2 \mathrm{~min}$ ), followed by 40 cycles of amplification program $\left[95^{\circ} \mathrm{C}\right.$ for $15 \mathrm{~s}$, gene-specific annealing temperature (Supplementary file 1, panel A) for $30 \mathrm{~s}$ and 
Table 1

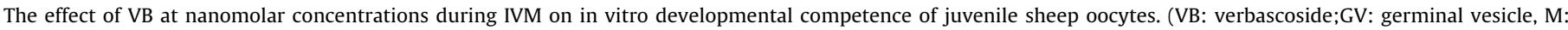
metaphase, T: telophase). a vs b vs c $\mathrm{P}<0.05$.

\begin{tabular}{|c|c|c|c|c|c|c|c|c|}
\hline \multirow{2}{*}{$\begin{array}{l}\text { VB concentration } \\
(\mathrm{nM})\end{array}$} & \multirow{2}{*}{$\begin{array}{l}\text { Exposure time } \\
\text { (h) }\end{array}$} & \multirow[t]{2}{*}{$\mathrm{n}^{\circ}$ oocytes } & \multicolumn{2}{|c|}{ Nuclear chromatin } & \multicolumn{2}{|c|}{ configuration number (\%) } & \multirow{2}{*}{$\begin{array}{l}\mathrm{n}^{\circ} \text { cleaved embryos/ } \\
\text { MII oocytes (\%) }\end{array}$} & \multirow{2}{*}{$\begin{array}{l}\mathrm{n}^{\circ} \text { blastocysts/ } \\
\text { cleaved embryos (\%) }\end{array}$} \\
\hline & & & GV & MI to TI & degenerated & MII & & \\
\hline 0 & 0 & 340 & $\begin{array}{l}45 \\
(13.2)\end{array}$ & $\begin{array}{l}48 \\
(14.1)\end{array}$ & $\begin{array}{l}21 \\
(6.2)\end{array}$ & $\begin{array}{l}226 \\
(66.5)\end{array}$ & $\begin{array}{l}165^{a} \\
(73)\end{array}$ & $\begin{array}{l}45^{a} \\
(27.3)\end{array}$ \\
\hline 1 & 24 & 288 & $\begin{array}{l}37 \\
(12.9)\end{array}$ & $\begin{array}{l}39 \\
(13.5)\end{array}$ & $\begin{array}{l}16 \\
(5.6)\end{array}$ & $\begin{array}{l}196 \\
(68.0)\end{array}$ & $\begin{array}{l}156^{\mathrm{b}} \\
(79.6)\end{array}$ & $\begin{array}{l}59^{\mathrm{b}} \\
(37.8)\end{array}$ \\
\hline 1 & 2 & 311 & $\begin{array}{l}42 \\
(13.5)\end{array}$ & $\begin{array}{l}38 \\
(12.3)\end{array}$ & $\begin{array}{l}21 \\
(6.7)\end{array}$ & $\begin{array}{l}210 \\
(67.5 .)\end{array}$ & $\begin{array}{l}196^{c} \\
(93.3)\end{array}$ & $\begin{array}{l}46^{a} \\
(23.5)\end{array}$ \\
\hline 10 & 2 & 288 & $\begin{array}{l}41 \\
(14.2)\end{array}$ & $\begin{array}{l}37 \\
(12.5)\end{array}$ & $\begin{array}{l}22 \\
(7.7)\end{array}$ & $\begin{array}{l}189 \\
(65.6)\end{array}$ & $\begin{array}{l}160^{\mathrm{b}} \\
(84.6)\end{array}$ & $\begin{array}{l}37^{\mathrm{a}} \\
(23.1)\end{array}$ \\
\hline
\end{tabular}

$72{ }^{\circ} \mathrm{C}$ for $30 \mathrm{~s}$ ], a melting curve program $\left(65-95^{\circ} \mathrm{C}\right.$, starting fluorescence acquisition at $65^{\circ} \mathrm{C}$ and taking measurements at $10 \mathrm{~s}$ intervals until the temperature reached $95^{\circ} \mathrm{C}$ ) and finally a cooling step to $4{ }^{\circ} \mathrm{C}$. Fluorescence data were acquired during the $72{ }^{\circ} \mathrm{C}$ extension steps. In order to minimize handling variation, all samples to be compared were run on the same plate using a PCR master mix containing all reaction components apart from the sample. The sizes of RT-PCR products were further confirmed by gel electrophoresis on a 2\% agarose gel stained with Sybr Safe (Invitrogen) and visualized by exposure to blue light. The PCR products were sequenced (Model 3130 xl Genetic Analyzer; Applied Biosystems) after purification with the MinElute PCR purification kit (Qiagen) and sequence identities were confirmed with BLAST (http://www.ncbi.nlm.nih.gov/BLAST/). The relative quantification of gene expression was performed with the 2-ddCq method [46]. The expression analysis was performed by normalizing each target gene against the geometric mean of three internal reference genes [succinate dehydrogenase complex, subunit A (SDHA), Tyrosine 3-Monooxygenase/Tryptophan 5-Monooxygenase Activation Protein, Zeta (YWHAZ) and glucose 6-phosphate dehydrogenase $(G 6 P D H)]$. Before normalization, the stable expression of the reference genes among groups was assessed.

\subsection{Experimental design}

Experiment 1: Effects of VB supplementation at nanomolar concentrations on oocyte meiotic and developmental competence.

Firstly, the effects of VB supplementation at nanomolar concentrations during IVM on oocyte meiotic (Experiment 1a) and developmental competence (Experiment $1 \mathrm{~b}$ ) and on embryo quality (Experiment 1c) were analyzed. Verbascoside was added in the IVM medium at the concentration of $1 \mathrm{nM}$, for two incubation times ( $24 \mathrm{~h}$ and $2 \mathrm{~h}$ ) and at $10 \mathrm{nM}$ for $2 \mathrm{~h}$. In the $2 \mathrm{~h}$ exposure groups, after $2 \mathrm{~h}$ incubation with VB, oocytes were washed and cultured up to $24 \mathrm{~h}$ without VB. A group of oocytes were cultured in absence of VB, as controls (CTRL). Oocyte nuclear maturation, embryonic cleavage, blastocyst formation and quality were evaluated. Blastocyst quality was evaluated after 8 days of embryo culture.

The rationale for the VB strategy treatment derived from the results of our previous study (Dell'Aquila et al., 2014). Indeed, a pro-oxidant effect of VB had been noticed at micromolar concentrations after $24 \mathrm{~h}$ exposure. This pro-oxidant activity was thought to be due to excessively high VB concentrations as, in the same study, we found that the VB uptake in the COC is much higher (even one thousand-fold higher) than in HT-29 cell monolayers [33]. Thus, in order to figure out a possible antioxidant effect of $\mathrm{VB}$ on the $\mathrm{COC}$, VB concentration and/or exposure time were reduced, with the following conditions being tested: $1 \mathrm{nM}$ VB for $24 \mathrm{~h}$, with lowered VB concentration while keeping $24 \mathrm{~h}$ exposure; $10 \mathrm{nM}$ VB for $2 \mathrm{~h}$, with shortened exposure time with a higher VB concentration; and $1 \mathrm{nM}$ VB for $2 \mathrm{~h}$, with lowered VB concentration and shortened exposure time.
Experiment 2: Effects of 1 nM VB supplementation for 24 h on oocyte bioenergetic/oxidative status.

Based on the results of experiment 1, the experimental condition with $1 \mathrm{nM}$ VB in a continuative $24 \mathrm{~h}$ IVM protocol was selected for subsequent studies in experiment 2. In order to explore the hypothesis that VB may induce its beneficial antioxidant effects on ooplasmic quality, VB-treated and control oocytes at the MII stage were analyzed for: (1) $\mathrm{mt}$ distribution pattern and activity, intracellular ROS localization and levels and mt/ROS colocalization by laser scanning confocal microscopy (LSCM)-based imaging (Experiment 2a); (2) LPO by spectrophotometric assay (Experiment 2b); (3) gene expression of bioenergy/redox-related genes by Real Time RT-PCR (Experiment 2c). LSCM-imaging analyses were performed in single oocytes and mean \pm SD were analyzed; LPO assay and gene expression analysis were performed in oocyte groups and 4 replicates for each condition were analyzed.

\subsection{Statistical analysis}

The percentages of oocytes showing different chromatin configuration, nuclear maturation, cleavage and blastocyst developmental rates were analyzed among groups by the Chi-square test with Bonferroni's as post-hoc test. After testing for normality and equal variance using, respectively, the Kolmogorov-Smirnov and Levene tests, blastocyst cell number and gene expression data were analyzed by analysis of variance (ANOVA). These data were analyzed using the MINITAB Release 12.1 software package. The percentages of oocytes showing different $m t$ distribution patterns were analyzed by Chi-square test. MitoTracker CMTM Ros and DCF fluorescence intensities for quantification analysis of mt activity and intracellular ROS levels, respectively, mt/ROS colocalization coefficients and LPO data were compared by the Student's $t$-test (GraphPad software). Differences with $P<0.05$ were considered as statistically significant.

\section{Results}

3.1. Experiment 1: effects of VB supplementation at nanomolar concentrations on oocyte meiotic and developmental competence

With the aim of testing the effects of VB supplementation, at nanomolar concentrations, on oocyte meiotic and developmental competence, three IVM/IVF/IVEC replicates were performed and $\mathrm{n}=1227$ COCs were cultured and analyzed for subsequent steps of maturation, cleavage and blastocyst formation rates. Matured oocytes ( $n=821 / 1227,67 \%$ total maturation rate) underwent IVF and were assessed for cleavage (82\%, 677 cleaved embryos/821 MII oocytes) and blastocyst formation rates (28\%, 187 blastocysts/677 cleaved embryos). Blastocysts were evaluated for expansion and hatching and for total, ICM and TE cell number.

Experiment 1.a: VB at nanomolar concentrations does not affect oocyte meiotic maturation. 
After IVM, the percentage of oocytes that reached the MII stage did not differ among groups. Similarly, meiosis progression did not differ among groups. Indeed, the percentages of oocytes remaining at the GV or at the MI to TI stage and the percentages of degenerated oocytes were comparable among groups (Table 1).

Experiment 1.b: Supplementation with $1 \mathrm{nM}$ VB for $24 \mathrm{~h}$ improves embryo development to the blastocyst stage.

Significantly higher rates of oocytes cultured in presence of $1 \mathrm{nM} V B$ (either for $24 \mathrm{~h}$ or for $2 \mathrm{~h}$ exposure time) and $10 \mathrm{nM}$ VB for $2 \mathrm{~h}$ underwent early cleavage $30 \mathrm{~h}$ after IVF compared to controls (Table $1, \mathrm{P}<0.05$ ). Treatment for $2 \mathrm{~h}$ with VB $1 \mathrm{nM}$ significantly $(\mathrm{P}<0.05)$ increased the cleavage rate compared to $1 \mathrm{nM} 24 \mathrm{~h}$ and $10 \mathrm{nM} 2 \mathrm{~h}$ groups (Table $1, \mathrm{P}<0.05$ ). Embryonic developmental competence to the blastocyst stage was significantly enhanced by treatment with VB $1 \mathrm{nM} 24 \mathrm{~h}$ compared with control and other VB-treated groups (Table $1, \mathrm{P}<0.05$ ).

Experiment 1.c: Supplementation with $1 \mathrm{nM}$ VB for $24 \mathrm{~h}$ improves blastocyst quality.

Supplementation with VB $1 \mathrm{nM} 24 \mathrm{~h}$ significantly enhanced blastocyst expansion (Fig. 1, panel A; $\mathrm{P}<0.01$ ) compared to $1 \mathrm{nM}$ VB $2 \mathrm{~h}, 10 \mathrm{nM}$ VB $2 \mathrm{~h}$ and control. Total and TE blastocyst cell numbers increased significantly $(\mathrm{P}<0.01)$ in the $1 \mathrm{nM} 24 \mathrm{~h}$ VB group compared to $1 \mathrm{nM}$ VB $2 \mathrm{~h}$ and controls (Fig. 1, panel B). ICM blastocyst cell numbers were similar among VB treated groups but $1 \mathrm{nM}$ VB $24 \mathrm{~h}$ and $10 \mathrm{nM}$ VB $2 \mathrm{~h}$ groups showed significantly $(\mathrm{P}<0.01)$ higher numbers compared to controls. Fig. 1, panel $C$ shows an in vitro produced blastocyst obtained after IVM in presence of VB and observed under phase contrast microscopy (I) and epifluorescence microscopy after differential staining (II).

\subsection{Experiment 2: effects with $1 \mathrm{nM}$ VB supplementation for $24 \mathrm{~h}$ on oocyte bioenergy/oxidative status}

With the aim of testing the effects of $1 \mathrm{nM}$ VB on oocyte bioenergetic/redox status, six IVM replicates were performed and $n=381$ COCs (192 COCs treated with $1 \mathrm{nM} \mathrm{VB}$ for $24 \mathrm{~h}$ and 189 control COCs) were analyzed. Oocyte maturation rate was assessed by observing the 1 st PB (total maturation rate $63 \%, 239 / 381$ ) and no differences were found between groups (62\%, 120/192 versus 63\%, 119/189 for VB-treated and controls, respectively, $\mathrm{P}>0.05)$. Matured VB-treated $(n=120)$ and control oocytes $(n=119)$ were destined to LSCM ( $n=46 ; 26$ VB-treated and 20 control MII oocytes), LPO ( $n=73$; 34 VB-treated and 39 control MII oocytes) and gene expression analysis ( $\mathrm{n}=120,60$ VB-treated and 60 control MII oocytes).

Experiment 2.a: Supplementation with $1 \mathrm{nM}$ VB for $24 \mathrm{~h}$ reduces ROS levels in matured oocytes.

There was no effect of VB on ooplasmic mt distribution pattern, as both VB-treated $(n=23)$ and control $(n=12)$ oocytes showed homogeneously diffused small $\mathrm{mt}$ aggregates throughout the cytoplasm. Fig. 2, panel A shows a VB-treated (B3) and a control oocyte (A3), both having a homogeneous $m t$ distribution pattern. Moreover, VB did not affect mt activity, as no differences in fluorescence intensity emitted by the MitoTracker probe were revealed between groups (Fig. 2, panel A: B3 versus A3; panel B). Instead, it significantly reduced oocyte intracellular ROS levels and increased mt/ROS colocalization (Fig. 2, panel B; P<0.05). Fig. 2 (panel A) shows an oocyte showing lower ooplasmic ROS levels (B4 vs A4), more marked mt/ROS merge (B5 vs A5) and a broader yellow colocalization area (B6 vs A6) compared with the control oocyte.

Experiment 2.b: Supplementation with $1 \mathrm{nM}$ VB for $24 \mathrm{~h}$ reduces LPO in matured oocytes.

The LPO assay was adapted to decumulated MII oocytes by adjusting the minimum number of oocytes per group to get detectable MDA values, oocyte lysis conditions and lysate exposure time to assay reagents. Finally, 8 groups of 5 oocytes each, 4 of which cultured in presence of $1 \mathrm{nM}$ VB for $24 \mathrm{~h}$ and 4 controls were
A

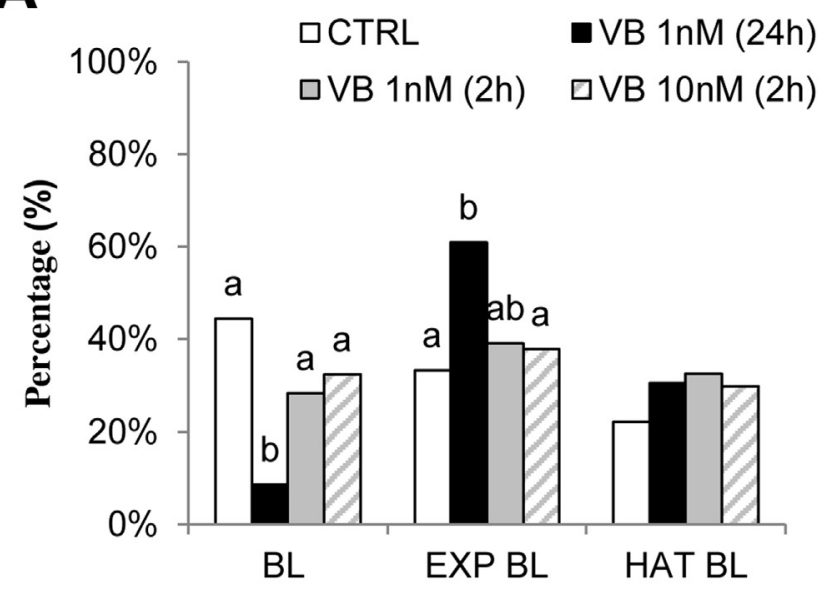

B

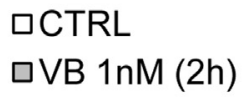

- VB $1 \mathrm{nM}(24 \mathrm{~h})$

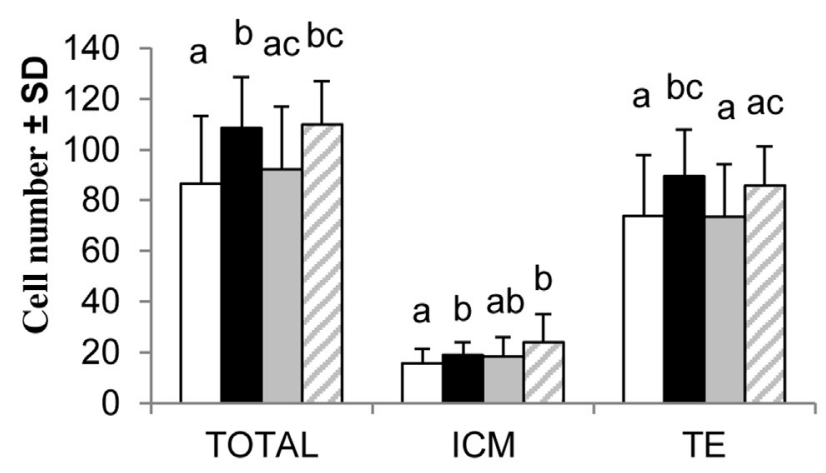

C
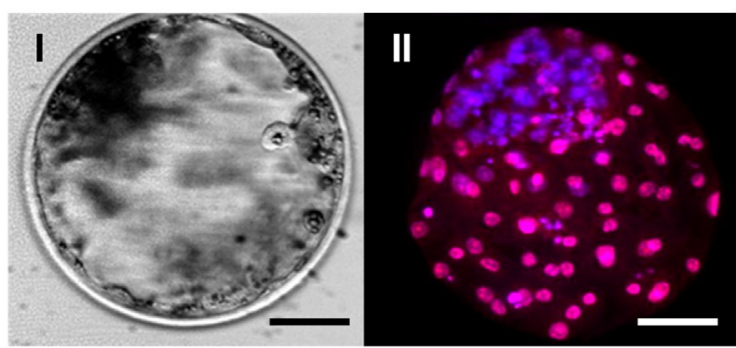

Fig. 1. Effects of VB supplementation at nanomolar concentrations during IVM on blastocyst quality. Panel A: Stage of blastocyst development at day 8 (BL: blastocyst; EXP BL: expanded blastocyst; HAT BL: hatching/hatched blastocyst). Panel B: Total, inner cell mass (ICM) and trophoectoderm (TE) cell number of blastocysts. Panel C: Expanded blastocyst obtained after IVM in presence of $1 \mathrm{nM}$ VB observed at day 8 under phase contrast microscopy (I) and under epifluorescent microscopy after differential staining (II). Within each end point, bars with different letter a,b,c are significantly different $(\mathrm{P}<0.01)$ for different VB treatments. Scale bars represent $40 \mu \mathrm{m}$.

analyzed. The addition of $1 \mathrm{nM}$ VB significantly reduced MDA levels, thus indicating a protective effect against LPO compared with controls (Fig. 2, panel C; $\mathrm{P}<0.05$ ).

Experiment 2.c: Supplementation with $1 \mathrm{nM}$ VB for $24 \mathrm{~h}$ does not alter oocyte expression of bioenergy/redox-related genes.

Six replicates of 10 oocytes each were analyzed for each experimental condition. The relative quantification of the transcripts 

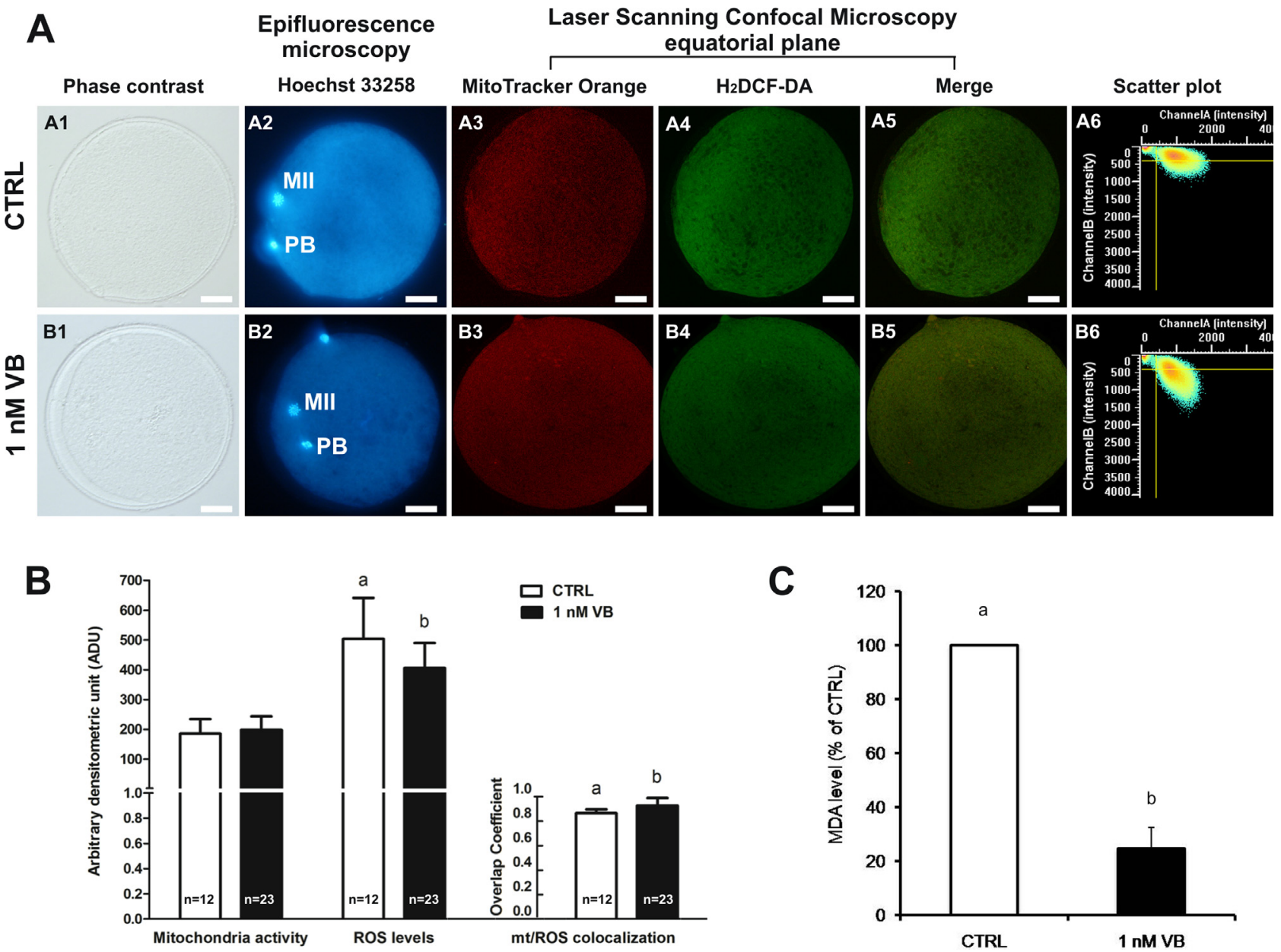

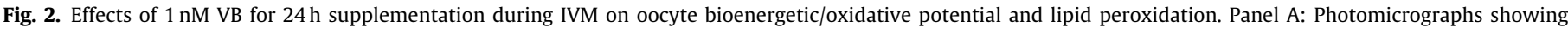

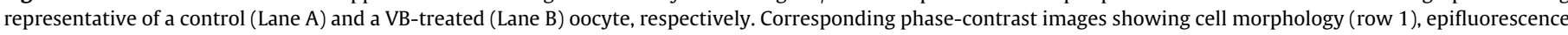

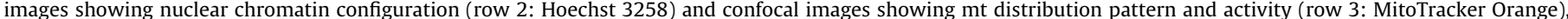

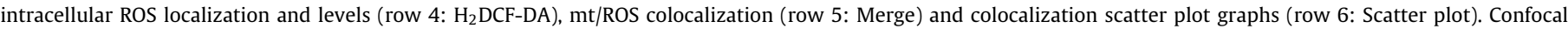

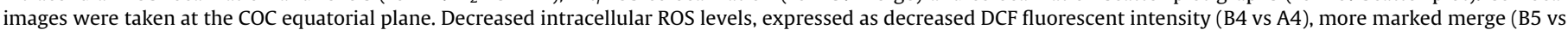

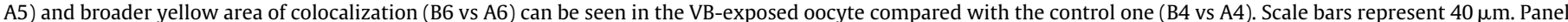

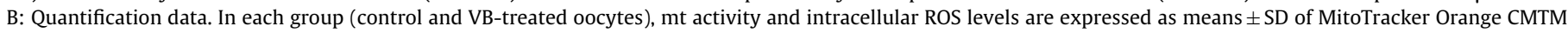

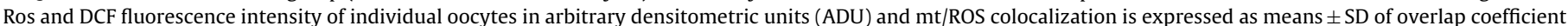

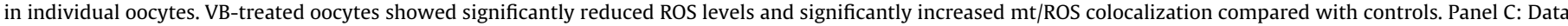

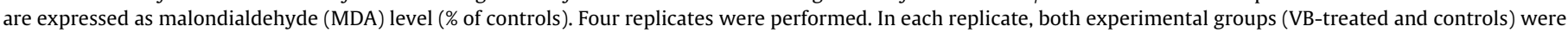

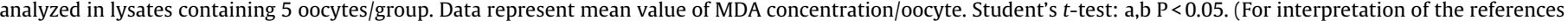
to colour in this figure legend, the reader is referred to the web version of this article.)

showed no differences between control and VB-treated MII oocytes, as comparable mRNA abundance of tested genes was observed after exposure to VB during IVM (Supplementary file 1, panel B).

\section{Discussion}

In the present study, we demonstrated that VB treatment at nanomolar concentrations during oocyte IVM had beneficial effects on embryo development in the juvenile sheep model. The juvenile sheep model "per sé" was confirmed to be competent to embryo development, as previously reported $[47,48]$. Our data indicated that prolonged ( $24 \mathrm{~h}$ ) oocyte exposure to $1 \mathrm{nM}$ VB enhances embryo development to the blastocyst stage and embryo quality, while $2 \mathrm{~h}$ exposure induces a high cleavage rate after IVF without affecting blastocyst formation rate and quality. These findings indicate a long-term beneficial effect exerted by VB during $24 \mathrm{~h}$ IVM on oocyte cytoplasmic competence and, consequently, on embryo development. Conversely, in our previous study [33], a significant reduction in blastocyst formation rate and embryo quality was observed after exposure for $24 \mathrm{~h}$ to VB concentrations above $1 \mu \mathrm{M}$.
Therefore, in order to understand how VB, at nanomolar concentrations, may positively affect oocyte developmental competence, the bioenergetic/redox status of oocytes treated with $1 \mathrm{nM}$ VB for $24 \mathrm{~h}$ was analyzed and compared with that of control oocytes. This VB treatment was found not to affect oocyte apparent bioenergetic status, as no differences in mt distribution pattern and mt-specific probe fluorescence intensity (indicating the mass of active mitochondria) between groups were found, but it improved oocyte oxidative status, by reducing ROS generation and LPO occurring during IVM, as assessed by lower cytosolic ROS levels and MDA levels found in the LPO assay, compared with controls. These results differ from those obtained in our previous study [33] in which micromolar VB concentrations increased oocyte mt activity and intracellular ROS levels, and may indicate that nanomolar VB concentrations are able to keep the oocyte in its basal bioenergy status while micromolar VB concentrations may lead to excessively driven mitochondria activity. In order to explain these differences, the first issue is to evaluate whether and how VB enters the COC. In our previous study [33], VB-uptake experiments demonstrated that the compound is rapidly incorporated into the $\mathrm{COC}$ in a time- 
dependent manner with a maximum accumulation efficiency of about $0.2 \%$ after $30 \mathrm{~min}$. The uptake experiments also demonstrated that the amount of VB found in COCs is one thousand times higher (in the order of $\mathrm{nmol} / \mathrm{mg}$ proteins) than that found in Caco-2 and HT 29 human intestinal cell lines (in the order of pmol/mg proteins; $[3,49])$. These results are consistent with the hypothesis that the absorptive potential of the COC is approximately one thousand times higher than that of cultured cell lines. For this reason, in the present study, we chose to test the effects of nanomolar VB concentrations, one thousand times lower than those tested in our previous study [33].

Verbascoside exposure at $1 \mathrm{nM}$ for $24 \mathrm{~h}$ exerted a relevant antioxidant activity at oocyte level which was detectable in terms of significantly reduced intracellular ROS and increased mt/ROS colocalization, indicating scavenging activity of cytosolic ROS and re-establishment of oocyte health status. Moreover, VB antioxidant activity elicited a protective effect against oocyte LPO, as confirmed by lower MDA levels found in VB-treated oocytes compared with controls. Currently, LPO is considered as a major mechanism involved in the oxidative damage to cell structures and in toxicity processes leading to cell death [50,51]. Unsaturated fatty acids which are structural parts of the cell membranes are subjected to LPO by a non-enzymatic and free radical-mediated reaction chain. LPO products and by-products are cytotoxic and lead, in successive steps, to oxidative damage and apoptosis [50]. As hypothesized by previous studies, appropriate antioxidants could keep sensitive cells in healthy conditions, avoiding LPO, thus prolonging their lifespan [50]. To the best of our knowledge, this is the first study reporting a MDA-based LPO assay used in the oocyte and this assay was adapted to the oocyte. Our data demonstrate that in vitro exposure to nanomolar VB concentration protects the oocyte against LPO and are in line with previous observations on the protective effect of VB against LPO in other cell systems [2,52,53]. In our previous study, VB increased intracellular ROS without affecting $\mathrm{mt} /$ ROS colocalization [33], thus inducing oxidative stress in the oocyte which is known to be linked to impaired capacity to support embryo development [54]. The antioxidant effects of VB could be of great relevance for in vitro therapeutical applications in human ARTs, because oxidative stress impairs oocyte quality in women exposed to different toxic conditions, such as tobacco, alcohol, medical drugs and environmental pollutants or in women affected by stress-related forms of infertility [11-13] and may also occur in oocytes with suboptimal meiotic and developmental competence, such as those from young girls $[30,31]$ or women in advanced reproductive age [55].

The results of expression analysis suggest that the beneficial effect of VB was not mediated by a molecular response of the panel of genes at the ooplasmic level. Indeed, VB exposure did not affect oocyte expression of any analyzed gene. Previous studies reported that natural antioxidants are able to affect ooplasmic transcriptional activity. For instance, resveratrol was reported to reduce the expression level of PCNA, POU5F1, BAX, BAK and Caspase 3 when used at 2 and $10 \mu \mathrm{M}$ in oocytes of prepubertal gilts [22]; to reduce $B A X$ expression when used at 0.25 e $0.5 \mu \mathrm{M}$ in oocytes from adult goats [23] and to up-regulate the expression of genes involved in oocyte maturation (c-mos; ERK2 and MAPK1) when used at 0.1, 1 e $10 \mu \mathrm{M}$ in bovine oocytes [24]. The lack of effects of VB on ooplasmic expression levels of examined metabolism- and stress-related genes could be in line with the lack of effects observed on mitochondria activity, as VB, at nanomolar levels, may have exerted a scavenging activity of ROS produced during IVM while keeping the oocyte in its basal bioenergy status. Modified expression levels observed in previous studies may be explained by the higher antioxidant concentrations used (ranging from $250 \mathrm{nM}$ and $10 \mu \mathrm{M}$ ). To the best of our knowledge, this is the first study investigating the effects of VB on ooplasmic gene expression; however, it cannot be excluded that the beneficial role of VB on embryo yield and quality could be mediated by differences in oocyte expression of other genes.

\section{Conclusions}

In conclusion, VB supplementation at nanomolar concentrations during IVM improves cleavage rate of oocytes after IVF. However, only $1 \mathrm{nM}$ VB for $24 \mathrm{~h}$ had a beneficial effect on embryo development to the blastocyst stage and blastocyst quality by acting as an antioxidant molecule, as it reduces oocyte ROS and LPO, while keeping mitochondria activity at basal levels. In addition, VB was shown to be a more active natural antioxidant on oocyte maturation and embryo production, as it determined its beneficial effects at nanomolar concentrations, considerably lower levels than the other antioxidants reported to date, acting at micromolar concentrations.

\section{Authors' contributions}

NAM and FA contributed equally to this work; MED and LB contributed equally to this work. MED, LB, NAM and FM designed the study, analyzed data and wrote the paper. NAM, FA, DB, MFU, ACh, GM, AG conducted experimental procedures of the study and collaborated in analyzing data and drafting the paper. MED, LB, ACa, FM, AMS, NAM supervised experiments and performed critical data analysis. All authors read and approved the paper.

\section{Study funding/competing interest(s)}

NAM was granted by the project ONEV MIUR PONa3 00134-n.254/R\&C $18 / 05 / 2011$ and by the project GR-201102351396 (Ministry of Health, Young Researchers Grant 2011/2012). FM, AC and AG were supported by PIF MIS 124 Olio Pugliese Federiciano (PSR PUGLIA 2007-2013 REP. 241 dated 21/12/2011). The authors have no conflicts of interest to disclose.

\section{Appendix A. Supplementary data}

Supplementary data associated with this article can be found, in the online version, at http://dx.doi.org/10.1016/j.reprotox.2016. 08.004.

\section{References}

[1] M. D'Imperio, A. Cardinali, I. D’Antuono, V. Linsalata, F. Minervini, B.W. Redanb, et al., Stability-activity of verbascoside a known antioxidant compound, at different pH conditions, Food Res. Int. 66 (2014) 373-378.

[2] K. Alipieva, L. Korkina, I.E. Orhan, M.I. Georgiev, Verbascoside-a review of its occurrence: (bio)synthesis and pharmacological significance, Biotechnol. Adv. 32 (2014) 1065-1076.

[3] A. Cardinali, S. Pati, F. Minervini, I. D’Antuono, V. Linsalata, V. Lattanzio, Verbascoside isoverbascoside, and their derivates recovered from olive mill wastewater as possible food antioxidants, J. Agr. Food Chem. 60 (2012) $1822-1829$

[4] V.A. Kostyuk, A. Potapovich, T.O. Suhan, C. De Luca, L.G. Korkina, Antioxidant and signal modulation properties of plant polyphenols in controlling vascular inflammation, Eur. J. Pharmacol. 658 (2011) 248-256

[5] S. Pastore, D. Lulli, P. Fidanza, A.I. Potapovich, V.A. Kostyuk, C. De Luca, et al., Plant polyphenols regulate chemokine espression and tissue repair in human keratinocytes through interaction with cytoplasmic and nuclear components of epidermal growth factor receptor system, Antioxid. Redox Signal. 16 (2012) 314-328.

[6] S.V. Kostyuk, M.S. Konkova, E.S. Ershova, A.J. Alekseeva, T.D. Smirnova, S.V. Stukalov, et al., An exposure to the oxidized DNA enhances both instability of genome and survival in cancer cells, PLoS One 8 (2013) e77469.

[7] A. Sgarbossa, M. Dal Bosco, G. Pressi, S. Cuzzocrea, R. Dal Toso, M. Menegazzi, Phenylpropanoid glycosides from plant cell cultures induce heme oxygenase 1 gene expression in a human keratinocyte cell line by affecting the balance of NRF2 and BACH1 transcription factors, Chem. Biol. Interact. 199 (2012) 87-95. 
[8] L.G. Korkina, V. Kostyuk, C. De Luca, S. Pastore, Plant phenylpropanoids as emerging anti-inflammatory agents, Mini-Rev. Med. Chem. 11 (2011) 823-835.

[9] A.I. Potapovich, D. Lulli, P. Fidanza, V.A. Kostyuk, C. De Luca, S. Pastore, et al., Plant polyphenols differentially modulate inflammatory responses of human keratinocytes by interfering with activation of transcription factors NFKB and AhR and EGFR-ERK pathway, Toxicol. Appl. Pharmacol. 255 (2011) 138-149.

[10] Z. Papoutsi, E. Kassi, S. Mitakou, N. Aligiannis, A. Tsiapara, G.P. Chrousos, et al., Acteoside and martynoside exhibit estrogenic/antiestrogenic properties, J. Steroid Biochem. Mol. Biol. 98 (2006) 63-71.

[11] E.H. Ruder, T.J. Hartman, M.B. Goldman, Impact of oxidative stress on female fertility, Curr. Opin. Obstet. Gynecol. 21 (2009) 219-222.

[12] K.H. Al-Gubory, P.A. Fowler, C. Garrel, The roles of cellular reactive oxygen species: oxidative stress and antioxidants in pregnancy outcomes, Int. J. Biochem. Cell Biol. 42 (2010) 1634-1650.

[13] A. Agarwal, A. Aponte-Mellado, B.J. Premkumar, A. Shaman, S. Gupta, The effects of oxidative stress on female reproduction: a review, Reprod. Biol. Endocrinol. 10 (2012) 49.

[14] D.G. de Matos, C.C. Furnus, The importance of having high glutathione (GSH) level after bovine in vitro maturation on embryo development effect of beta mercaptoethanol cysteine and cystine, Theriogenology 53 (2000) 761-771.

[15] M. Kobayashi, E.S. Lee, Y. Fukui, Cysteamine or beta-mercaptoethanol added to a defined maturation medium improves blastocyst formation of porcine oocytes after intracytoplasmic sperm injection, Theriogenology 65 (2006) 1191-1199.

[16] B.D. Whitaker, J.W. Knight, Effects of N-acetyl-cysteine and $\mathrm{N}$-acetyl-cysteine-amide supplementation on in vitro matured porcine oocytes, Reprod. Domest. Anim. 45 (2010) 755-759.

[17] L. Zhang, A.S. Ravipati, S.R. Koyyalamudi, S.C. Jeong, N. Reddy, P.T. Smith, et al., Antioxidant and anti-inflammatory activities of selected medicinal plants containing phenolic and flavonoid compounds, J. Agric. Food Chem. 59 (2011) $12361-12367$

[18] H.F. Ji, X.J. Li, H.Y. Zhang, Natural products and drug discovery. Can thousand of years of ancient medical knowledge lead us to new and powerful drug combinations in the fight against cancer and dementia? EMBO Rep. 10 (2009) 194-200.

[19] J. You, J. Kim, J. Lim, E. Lee, Anthocyanin stimulates in vitro development of cloned pig embryos by increasing the intracellular glutathione level and inhibiting reactive oxygen species, Theriogenology 74 (2010) 777-785.

[20] C. Gao, H.B. Han, X.Z. Tian, D.X. Tan, L. Wang, G.B. Zhou, et al., Melatonin promotes embryonic development and reduces reactive oxygen species in vitrified mouse 2-cell embryos, J. Pineal Res. 52 (2012) 305-311.

[21] F. Wang, X. Tian, L. Zhang, D. Tan, R.J. Reiter, G. Liu, Melatonin promotes the in vitro development of pronuclear embryos and increases the efficiency of blastocyst implantation in murine, J. Pineal Res. 55 (2013) 267-274.

[22] S.S. Kwak, S.A. Cheong, Y. Jeon, E. Lee, K.C. Choi, E.B. Jeung, et al., The effects of resveratrol on porcine oocyte in vitro maturation and subsequent embryonic development after parthenogenetic activation and in vitro fertilization, Theriogenology 78 (2012) 86-101.

[23] A. Mukherjee, H. Malik, A.P. Saha, A. Dubey, D.K. Singhal, S. Boateng, et al., Resveratrol treatment during goat oocytes maturation enhances developmental competence of parthenogenetic and hand-made cloned blastocysts by modulating intracellular glutathione level and embryonic gene expression, J. Assist. Reprod. Genet. 31 (2014) 229-239.

[24] F. Wang, X. Tian, L. Zhang, C. He, P. Ji, Y. Li, et al., Beneficial effect of resveratrol on bovine oocyte maturation and subsequent embryonic development after in vitro fertilization, Fertil. Steril. 101 (2014) 577-586.

[25] C. Yasmin, T. Otoi, M.A. Setiadi, N.W. Karja, Maturation and fertilisation of sheep oocytes cultured in serum-free medium containing silk protein sericin, Acta Vet. Hung. 63 (2015) 110-117.

[26] B.K. Campbell, C. Souza, J. Gong, R. Webb, N. Kendall, P. Marsters, et al., Domestic ruminants as models for the elucidation of the mechanisms controlling ovarian follicle development in humans, Reprod. Suppl. 61 (2003) 429-443.

[27] M. Cotterill, S.E. Harris, E.C. Fernandez, J. Lu, J.D. Huntriss, B.K. Campbell, et al., The activity and copy number of mitochondrial DNA in ovine oocytes throughout oogenesis in vivo and during oocyte maturation in vitro, Mol. Hum. Reprod. 19 (2013) 444-450.

[28] G.G. Leoni, M.G. Palmerini, V. Satta, S. Succu, V. Pasciu, A. Zinellu, et al., Differences in the kinetic of the first meiotic division and in active mitochondrial distribution between prepubertal and adult oocytes mirror differences in their developmental competence in a sheep model, PLoS One 10 (2015) e0124911.

[29] D.T. Baird, Factors regulating the growth of the preovulatory follicle in the sheep and human, J. Reprod. Fertil. 69 (1983) 343-352.

[30] L. Ayensu-Coker, D. Bauman, S.R. Lindheim, L. Breech, Fertility preservation in pediatric: adolescent and young adult female cancer patients, Pediatr. Endocrinol. Rev. 10 (2012) 174-187.

[31] D.E. Reichman, O.K. Davis, N. Zaninovic, Z. Rosenwaks, D.E. Goldschlag, Fertility preservation using controlled ovarian hyperstimulation and oocyte cryopreservation in a premenarcheal female with myelodysplastic syndrome, Fertil. Steril. 98 (2012) 1225-1228.
[32] A. Langbeen, H.F. De Porte, E. Bartholomeus, J.L. Leroy, P.E. Bols, Bovine in vitro reproduction models can contribute to the development of (female) fertility preservation strategies, Theriogenology 84 (2015) 477-489.

[33] M.E. Dell'Aquila, L. Bogliolo, R. Russo, N.A. Martino, M. Filioli Uranio, F. Ariu, et al., Prooxidant effects of verbascoside, a bioactive compound from olive oil mill wastewater, on in vitro developmental potential of ovine prepubertal oocytes and bioenergetic/oxidative stress parameters of fresh and vitrified oocytes, BioMed. Res. Int. (2014) 878062

[34] A. Cardinali, F. Rotondo, F. Minervini, V. Linsalata, I. D’Antuono, L. De Bellis, et al., Assessment of verbascoside absorption in human colonic tissues using the Ussing chamber model, Food Res. Int. 54 (2013) 132-138.

[35] L. Bogliolo, F. Ariu, G. Leoni, S. Uccheddu, D. Bebbere, High hydrostatic pressure treatment improves the quality of in vitro-produced ovine blastocysts, Reprod. Fertil. Dev. 23 (2011) 809-817.

[36] N.A. Martino, G.M. Lacalandra, M. Filioli Uranio, B. Ambruosi, M. Caira, F. Silvestre, et al., Oocyte mitochondrial bioenergy potential and oxidative stress: within-/between-subject in vivo versus in vitro maturation, and age-related variations in a sheep model, Fertil. Steril. 97 (2012) 720-728.

[37] D. Bebbere, F. Ariu, L. Bogliolo, L. Masala, O. Murrone, M. Fattorini, et al., Expression of maternally derived KHDC3, NLRP5, OOEP and TLE6 is associated with oocyte developmental competence in the ovine species, BMC Dev. Biol. 14 (2014) 40

[38] H.R. Tervit, D.G. Whittingham, L.E. Rowson, Successful culture in vitro of sheep and cattle ova, J. Reprod. Fertil. 30 (1972) 493-497.

[39] S.K. Walker, J.L. Hill, D.O. Kleemann, C.D. Nancarrow, Development of ovine embryos in synthetic oviductal fluid containing amino acids at oviductal fluid concentrations, Biol. Reprod. 55 (1996) 703-708.

[40] T.C. Cheng, C.C. Huang, L.S. Huang, C.I. Chen, M.S. Lee, J.Y. Liu, Evaluation of mouse blastocyst implantation rate by morphology grading, Chin. J. Physiol. 47 (2004) 43-47.

[41] G.A. Thouas, N.A. Korfiatis, A.J. French, G.M. Jones, A.O. Trounson, Simplified technique for differential staining of inner cell mass and trophectoderm cells of mouse and bovine blastocysts, Reprod. Biomed. Online 3 (2001) 25-29.

[42] M. Romek, B. Gajda, M. Rolka, Z. Smorąg, Mitochondrial activity and morphology in developing porcine oocytes and pre-implantation non-cultured and cultured embryos, Reprod. Domest. Anim. 46 (2011) 471-480.

[43] W.F. Marei, D.C. Wathes, A.A. Fouladi-Nashta, Differential effects of linoleic and alpha-linolenic fatty acids on spatial and temporal mitochondrial distribution and activity in bovine oocytes, Reprod. Fertil. Dev. 24 (2012) 679-690.

[44] S.L. Wakefield, M. Lane, S.J. Schulz, M.L. Hebart, J.G. Thompson, M. Mitchell, Maternal supply of omega-3 polyunsaturated fatty acids alter mechanisms involved in oocyte and early embryo development in the mouse, Am. J. Physiol. Endocrinol. Metab. 294 (2008) 425-434.

[45] S. Amara, H. Abdelmelek, C. Garrel, P. Guiraud, T. Douki, J.L. Ravanat, et al. Preventive effect of zinc against cadmium-induced oxidative stress in the rat testis, J. Reprod. Dev. 54 (2008) 129-134.

[46] K.J. Livak, T.D. Schmittgen, Analysis of relative gene expression data using real-time quantitative PCR and the 2-Delta Delta CT Method, Methods 25 (2001) 402-408.

[47] S. Ledda, L. Bogliolo, P. Calvia, G. Leoni, S. Naitana, Meiotic progression and developmental competence of oocytes collected from juvenile and adult ewes, J. Reprod. Fertil. 109 (1997) 73-78.

[48] G.G. Leoni, D. Bebbere, S. Succu, F. Berlinguer, F. Mossa, M. Galioto, et al., Relations between relative bundance and developmental competence of ovine oocytes Mol, Reprod. Dev. 74 (2007) 249-257.

[49] A. Cardinali, V. Linsalata, V. Lattanzio, M.G. Ferruzzi, Verbascoside from olive mill waste water: assessment of their bioaccessibility and intestinal uptake using an in vitro digestion/Caco-2 model system, J. Food Sci. 76 (2011) 48-54.

[50] M. Repetto, J. Semprine, A. Boveris, Lipid peroxidation: chemical mechanism, biological implications and analytical determination, InTech (2012) 3-30, http://dx.doi.org/10.5772/45943, Chapter 1.

[51] A. Ayala, M.F. Munoz, S. Arguelles, Lipid peroxidation: production, metabolism and signaling mechanisms of Malondialdehyde and 4-hydroxy-2-noneal, Oxid. Med. Cell. Longevity (2014), http://dx.doi.org/10. 1155/2014/360438, Article ID 360438.

[52] J.X. Li, D. Xin, H. Li, J.F. Lu, C.W. Tong, J.N. Gao, et al., Effect of verbascoside on decreasing concentration of oxygen free radicals and lipid peroxidation in skeletal muscle, Zhongguo Yao Li Xue Bao 20 (1999) 126-130.

[53] L. Funes, S. Fernandez-Arroyo, O. Laporta, A. Pons, E. Roche, A. Segura-Carretero, Correlation between plasma antioxidant capacity and verbascoside levels in rats after oral administration of lemon verbena extract, Food Chem. 117 (2009) 589-598.

[54] T. Lord, R.J. Aitken, Oxidative stress and ageing of the post-ovulatory oocyte, Reproduction 146 (2013) 217-227

[55] D.R. Meldrum, R.F. Casper, A. Diez-Juan, C. Simon, A.D. Domar, R. Frydman, Aging and the environment affect gamete and embryo potential: can we intervene? Fertil. Steril. (2016), S0015-0282(16)00048-0. 